\title{
La falsa oposición entre teoría y práctica en la educación jurídica
}

The false opposition between theory and practice in legal education

\section{Ilsse Carolina Torres Ortega \\ Profesora investigadora en el Departamento de Estudios Sociopolíticos y Jurídicos Instituto Tecnológico de Estudios Superiores de Occidente (ITESO), México. E-mail: torresilsse@iteso.mx}

\begin{abstract}
Resumen: Este trabajo tiene por objeto discutir la pertinencia de la oposición entre teoría y práctica en la enseñanza del Derecho. Para llevar a cabo lo anterior, la autora explora la posibilidad de que tal oposición esté siendo utilizada como un mecanismo falaz que lleva a enfrentar cuestiones que, en realidad, están interrelacionadas. Esta exploración se desarrolla distinguiendo diversos sentidos de teoría y de práctica, concluyendo que es necesario reconstruir estas nociones de una manera más adecuada, atendiendo a las actividades que realizan -y/o deberían realizar- los juristas y que, por tanto, tendrían que estar presentes en la educación de los futuros profesionales del Derecho.
\end{abstract}

Palabras clave: Derecho; educación jurídica; falsa oposición; teoría; práctica.

\begin{abstract}
This paper discusses the relevance of the opposition between Theory and Practice in Law Education. The author explores the possibility that such opposition is being used as a fallacy tool that leads to confronting issues that, in reality, are interrelated. To do this, it distinguishes various senses of theory and practice, reflecting
\end{abstract}


on the need to rebuild these notions in a better way, taking into account the activities carried out -and / or should be carried out- by jurists and, therefore, would have to be present in the education of future law professionals.

Keywords: Law; Legal education; False Opposition; Theory; Practice.

\section{El paralogismo de la falsa oposición}

Vaz Ferreira dedica su conocida obra Lógica viva al análisis y a la reconstrucción de algunos mecanismos -empleados con inmoderada frecuencia- que dan lugar a argumentos falaces. Así, dentro de una disertación dirigida a esclarecer un problema respecto del cual hay diversas posiciones en conflicto, uno de estos mecanismos consiste en crear falsos dilemas o falsas oposiciones, tomando por contradictorio lo que es, en muchos casos, complementario (o, como en el caso que yo analizaré, más que complementario, se trata de cuestiones interrelacionadas). Lo anterior consiste en un razonamiento aparentemente válido, pero que no lo es, por lo que se trata de una falacia: la falacia de la falsa oposición. Esta falacia está tan arraigada en nuestros razonamientos que gran parte de las teorías, opiniones, observaciones, etc. de distintos ámbitos del conocimiento que se tratan como opuestas, no lo son (Vaz Ferreira, 1979: 7).

En el contexto de la reflexión sobre la educación jurídica hay también múltiples ejemplos de falsa oposición. Aquí se tratará uno específico que consiste en la afirmación de que la enseñanza jurídica ha de ser, o bien teórica, o bien práctica ${ }^{1}$.

Cualquiera que haya estado en una facultad de Derecho habrá escuchado en innumerables ocasiones que hay profesores teóricos y otros que son prácticos, de lo cual se seguiría, en principio, que los cursos impartidos por tales profesores (tanto el

\footnotetext{
${ }^{1}$ En la literatura hay incontables ejemplos de esta falacia. Veamos el siguiente ejemplo contenido en un artículo de Héctor Fix-Zamudio: "Debido a esta exageración tradicional de nuestros estudios jurídicos, abrumadoramente teóricos, se está abriendo paso entre los tratadistas latinoamericanos deseosos de superar el abuso de la "dogmática", una inclinación por los llamados estudios "empíricos", siguiendo el ejemplo de un sector de juristas angloamericanos, especialmente estadounidenses, el que ha señalado la necesidad de reducir el predominio de los que se han calificado de manera peyorativa como book teachers y superar la dicotomía, en ocasiones insalvables, entre los dos conceptos de law in book y law en action" (Fix-Zamudio, 1995: 80 y 81). En este caso, el autor más adelante rechaza tal oposición, aunque solo de manera aparente, puesto que persiste en el tratamiento de teoría y práctica como dos ingredientes separados que hemos de mezclar de manera equilibrada.
} 
conocimiento, los métodos de enseñanza, las habilidades, etc.) son susceptibles de caracterizarse con el mismo adjetivo ${ }^{2}$. También suele ocurrir que, ante tal creencia, el juicio rápido que se erige para elegir cuál de estos dos modelos - de profesor y de cursoes mejor para el campo del Derecho se ve notoriamente inclinado hacia lo práctico. Así, aquellos juristas que "enseñan" teoría -la cual, en este punto, adquiere incluso un tono peyorativo- tienen poco a nada que hacer en una facultad de Derecho, puesto que los futuros profesionales de esta área no necesitan aprender elucubraciones teóricas: lo que requieren es conocer la realidad, el Derecho que es, la práctica en su sentido más mundano.

El problema de un (mal) razonamiento construido a partir de una falsa dicotomía es que las alternativas que propone, en realidad, no compiten entre ellas; esto lo convierte en un planteamiento confuso y equivocado. Sin embargo, este problema llega a ser más serio: de la elección de una de las alternativas se sigue que la otra ha sido derrotada. Esto es, la falacia de la falsa oposición es un recurso retórico - persuasivo- esgrimido para mermar la credibilidad o el valor de una de las alternativas. El sofisma radica en que hay una exageración de una de las posturas que condena a la otra cuando la muestra como incompatible con la primera. Así, en nuestro objeto de interés, si es verdad que la educación jurídica ha de ser eminentemente práctica, entonces la teoría se presenta como algo que ha de ser desechado de este ámbito.

Como se intentará mostrar a continuación, esta última afirmación está afectada por el paralogismo de la falsa oposición, tomando por contradictorio algo que es complementario -aunque solo en una buena reconstrucción de lo que se puede entender por teoría y práctica-. Por un lado, la reflexión teórica del Derecho no es adecuada ni

\footnotetext{
${ }^{2}$ Nótese que hay una marcada ambigüedad acerca de si el carácter teórico o práctico se predica del profesor (su origen) o de su actividad docente. El estereotipo del profesor teórico sería el de una persona que proviene de la academia, interesado en la investigación y que cultiva alguna de las disciplinas dogmáticas del Derecho. Suele tratarse de un profesor de tiempo completo que desarrolla su vida profesional centralmente en el ambiente académico. El estereotipo del profesor práctico, en cambio, suele estar representado por un operador jurídico en activo que solo participa ocasionalmente en la vida académica; por ejemplo, un abogado litigante, un juez o un secretario judicial. Sin embargo, como más adelante se verá, el origen del profesor -práctico o teórico- no condiciona un tipo de docencia específica y, por tanto, no puede tomarse como la causa de los efectos que deseamos evitar en nuestras facultades de Derecho. Si fuera de esta forma, la solución para tener una educación jurídica más práctica sería simplemente conseguir que los docentes fueran en su mayoría operadores jurídicos (algo que, de hecho, ya sucede en Latinoamérica).
} 
resulta útil si no tiene en cuenta el tipo de problemas que caracterizan lo jurídico ni el contexto práctico en el que el Derecho se desarrolla. Por otra parte, todo ejercicio práctico del Derecho se sostiene en una teoría, aunque en no pocas ocasiones cuesta reconocerlo y, más importante aún, reflexionar sobre qué teoría del Derecho estamos reproduciendo con nuestro quehacer jurídico.

Ahora bien, todo lo que se acaba de anotar sería ocioso si entre la teoría y la práctica del Derecho existiera una genuina oposición. Y para poder afirmar o negar lo anterior es necesario indagar un poco acerca de qué podemos entender por teoría y por práctica en el contexto de la educación jurídica.

\section{Teoría y práctica en la educación jurídica}

Pese a lo antes anotado, no pretende insinuarse que la denuncia de que la enseñanza jurídica es excesivamente teórica y que debe ser más práctica esté fuera de lugar o haya de tomarse a la ligera. Lo que se pone en duda es que el punto modal de este reclamo quede recogido en la oposición antes aludida. En realidad, parece que la aseveración de que la formación universitaria en Derecho no es lo suficientemente práctica es cierta, pero, como ahora se expondrá, esto sería así -curiosamente- porque le falta teoría (aunque no cualquier teoría). Esto quiere decir que habrá que reconstruir otros sentidos de teoría y de práctica más esclarecidos que los sentidos ordinarios que normalmente empleamos ${ }^{3}$.

Ocuparnos de estos conceptos e intentar dar cuenta de los sentidos relevantes en los que son empleados cumple una tarea central para lograr el entendimiento de cuestiones intrincadas. Tal y como indica Guillermo Lariguet, nos ocupamos de los conceptos por buenas razones: "No lo hacemos por prurito especulativo, sino porque queremos comprender los anclajes referenciales de nuestros conceptos que no son otros que estados de cosas, conductas, prácticas que parecen estar impregnadas, o al menos 'circundadas', por nuestros conceptos" (2016: 234). Así, a continuación se realiza un esfuerzo de análisis conceptual que tiene el propósito no solo de "diagnosticar" a qué

\footnotetext{
${ }^{3}$ Estoy haciendo referencia al sentido de teoría señalado por la Real Academia de la Lengua Española como "conocimiento especulativo considerado con independencia de toda aplicación" y de práctica como "destreza adquirida con el ejercicio de la práctica”. https://dle.rae.es/srv/fetch?id=ZVMWXKy
} 
nos referimos en el ámbito de educación jurídica cuando hablamos de teoría o de práctica, sino también de poder representar críticamente aquellos sentidos que mejor se ajustan al objetivo formativo de dicho ámbito.

\section{1. ¿Qué práctica?}

\section{Práctica 1 y Práctica 2}

Sobre esto último resulta ilustrativo lo que señala Pérez Lledó respecto a lo que suele entenderse por práctica en las aulas. La exigencia de que la educación debe ser más práctica está equivocada "cuando por 'práctica' los estudiantes están pensando en los aspectos menores, más de 'detalle' y, por tanto, más variados de las rutinas de la profesión. Están pensando en una noción muy estrecha de 'práctica', en aspectos y minucias 'procedimentales'... están pensando en la 'práctica' en el sentido trivial de 'saber rellenar papeles'", (2002: 206).

Es evidente que la práctica en el sentido de actividad, de habilidades o destrezas desarrolladas con base al aprendizaje experiencial (que se identificará como práctica 1) resulta adecuado para explicar una parte de la formación de los juristas, pero es insatisfactoria para dar cuenta en términos integrales de lo que hacen los profesionales del Derecho, especialmente en lo que respecta al razonamiento jurídico, al pensar como jurista.

Aunque pueda haber profesores y estudiantes aferrados a que en esto consiste el saber útil, resulta paradójico que, en realidad, una enseñanza basada en las reglas técnicas de la profesión es muy poco práctica. Y es que, en tanto que sería absurdo intentar abarcar tales minucias en la amplia variedad de profesiones jurídicas, estudiantes y profesores terminan por asumir que este aprendizaje solo puede ser adquirido fuera de la facultad de Derecho ${ }^{4}$. Esto último no deja de resultar paradójico, por no decir que, de ser cierto, se trataría de un auténtico fracaso del sistema de formación universitaria. Esta creencia, además, suele venir acompañada de la idea de que, esta gran dificultad de aprender

\footnotetext{
${ }^{4}$ Pérez Lledó señala que esta reivindicación más bien debe referirse a que la formación jurídica sea más metodológica, capacitando en general para el manejo del Derecho en estas diversas profesiones jurídicas (Pérez Lledó, 2002: 207).
} 
práctica 1 en las aulas, solo puede ser paliada con la ayuda de un perfil docente muy específico: el del jurista que ejercita en su día a día este tipo de práctica.

La paradoja a la que nos lleva esta concepción de la práctica llega aún más lejos; y para ilustrarlo se toma como referencia el razonamiento argüido por Carlos S. Nino para defender la conveniencia de cierto perfil de profesores en las facultades de Derecho (1988: 284 y 285). Veamos esto: 1- En nuestras instituciones educativas tiene mucho peso la idea de que el mejor profesor de Derecho es un jurista (del ámbito público o privado) prestigioso que va a impartir en las aulas la experiencia que recoge en su día a día. 2- En países como México, la mayor parte de la planta de profesores está compuesta por profesores de tiempo parcial; en el caso particular de la carrera de Derecho, los profesores de tiempo parcial son centralmente operadores jurídicos (diríamos, juristas prácticos). 3- Sin embargo, al mismo tiempo que aceptamos 1 y 2 como afirmaciones probablemente verdaderas, también afirmamos que lo que peor se enseña en las facultades de Derecho es la práctica profesional.

Por supuesto, las tesis anteriores son debatibles, pero sirve, al menos tentativamente, para ilustrar cómo si fuera cierto que la educación práctica consiste, centralmente, en la puesta en común que hace un jurista de su experiencia profesional, en un escenario como el que se acaba de mencionar no sería adecuado denunciar que la enseñanza jurídica es demasiado teórica. Lo anterior es, entonces, un indicativo de que son los propios profesores que llamamos prácticos -y también práctica 1 - quienes no están siendo lo suficientemente prácticos y que, por tanto, el sentido relevante de este concepto requiere de otros elementos.

Antes de avanzar en ello, vale la pena detenerse en otro sentido de práctica al que se ha aludido. Anteriormente se señaló que una educación jurídica centrada en el intento por transmitir todos los detalles de una actividad jurídica específica, teniendo en cuenta la diversidad de profesiones jurídicas y de escenarios en que se desenvuelven, sería muy poco práctica. Nótese que aquí se utiliza este adjetivo para referir algo distinto a práctica 1. En este sentido, lo práctico alude a aquello que sirve, que es pragmático. Este es un sentido que conviene tener presente al momento de elucidar la práctica en la enseñanza del Derecho y se le identificará como práctica 2. 
En principio, que algo sirva implica que es útil o apto para lograr ciertos objetivos o fines; que cumple una finalidad. Responde a una racionalidad de medio-fin, aunque esta forma de racionalidad no implique pronunciamiento alguno sobre el contenido de los medios y la determinación de los fines. Esto quiere decir que una versión no esclarecida de lo pragmático no tiene que ver con cuestiones de fondo.

Ahora bien, aquello que se considera que sirve, o que es útil, con frecuencia se relaciona con lo que priorizamos en nuestras sociedades mercantilizadas. Así, en muchas ocasiones son nuestros mercados los que nos indican lo que "sirve" y también su opuesto, es decir, lo que es inservible. Aquello que es calificado de inservible no solo envuelve un juicio acerca de su valor de utilidad, sino que conlleva una recomendación normativa -de deber ser- acerca de que lo inservible ha de ser desechado o, por lo menos, que no es merecedor de preservación.

A este sentido de lo pragmático, identificado como la mera "preferencia por lo práctico o útil ${ }^{5}$, , parece hacer referencia Marta Nussbaum cuando denuncia la tendencia mundial, en sociedades democráticas, a eliminar ciertos contenidos de la educación. Ella se centra en las humanidades, denunciando que los responsables políticos ven en las humanidades un "adorno inútil" ante el objetivo de ser naciones competitivas en el mercado global. Si esta tendencia continúa, nos dice, las naciones de todo el mundo pronto estarán produciendo generaciones de máquinas útiles, en lugar de ciudadanos completos que puedan pensar por sí mismos, criticar la tradición, trascender las lealtades locales y acercarse a los problemas mundiales como un "ciudadano del mundo" con la capacidad de imaginar comprensivamente la situación del otro (Nussbaum, 2016: 14).

Lo anterior pone de manifiesto que lo pragmático que se desentiende de aquello para lo que sirve, no puede ser el enfoque adecuado para formar profesionales que son, ante todo, ciudadanos que participan en una comunidad que procura el bienestar de sus miembros, tanto en la esfera de lo autorreferente, como en la de lo intersubjetivo. Como se verá un poco más adelante, las profesiones jurídicas son actividades sociales que tienen que legitimarse éticamente, lo que implica que la cuestión de los fines que

5 Este es el primer sentido al que alude la Real Academia de la Lengua Española: https://dle.rae.es/srv/search?m=30\&w=pragmatismo 
pretenden conseguirse a través de dichas actividades no puede dejarse en manos de los intereses particulares de ciertos sectores de la sociedad. Por ahora, conviene dejar anotado que práctica 2 apunta, sin embargo, a una cuestión sumamente importante: lo que se estudia en una universidad debe "servir" para algo; lo que sucede es que ese “algo" ha de estar fundamentado racionalmente como valioso.

\section{2. ¿Qué teoría?}

\section{Teoría 1 y teoría 2}

Para avanzar en esto último, antes hay que profundizar en el concepto de teoría. Para ello se distinguen dos sentidos que resultan relevantes para las ideas aquí presentadas. Por una parte, teoría ha de ser entendida como conocimiento racional, esto es, métodos generales necesarios para aprehender y sistematizar la información que vamos adquiriendo en nuestra vida. En este sentido, es verdad que quien teoriza realiza una actividad preponderantemente abstracta, puesto que se trata de una forma susceptible de aplicarse a un campo de conocimiento específico. Por otra parte, la teoría también puede ser entendida como el conjunto de conceptos, proposiciones generales y contenidos que conforman una determinada manera de entender una disciplina concreta. En nuestro contexto, se trataría de una concepción del Derecho que termina repercutiendo en qué se enseña del Derecho, cómo se enseña y qué se pretende con ello ${ }^{6}$. Al primero se le identificará como teoría 1 y al segundo como teoría 2 .

Lo primero que hay que señalar sobre teoría 1 y 2 es que, entre ellas, no hay en absoluto una oposición; más bien, hay una relación de especialidad de la segunda respecto de la primera. Con teoría 1, lo que se intenta reivindicar es que existe un razonamiento que es general y abstracto, el cual debe funcionar como presupuesto de cualquier tipo de razonamiento más específico. Se está pensando, por ejemplo, en el estudio de la lógica y la argumentación.

\footnotetext{
${ }^{6}$ Con esto se pretende dar cuenta de lo que Böhmer llama "concepción general de la enseñanza del Derecho", para la cual señala que hay que considerar tres cuestiones: a) concepción del Derecho; 2) las formas de enseñarlo; y 3) los objetivos de la enseñanza. Este autor considera que estas tres cuestiones permiten reconstruir esta concepción e identificar cuál está siendo privilegiada en una facultad de Derecho (1999: 14).
} 
La lógica es necesaria para el jurista porque, para poder razonar jurídicamente, es necesario que el jurista sepa, en primer lugar, qué es razonar en general. A esto se refiere Lorenzo Peña cuando afirma que:

Ante todo es menester reivindicar que el razonar jurídico no puede ser sino un caso particular del razonar en general. La operación mental es la misma: pasar de la afirmación (o, al menos, la admisión hipotética) de unas premisas a la de una conclusión mediante reglas de inferencia lógicas (que pueden ser deductivas, inductivas y abductivas). La esencia del razonamiento, aquello que marca su diferencia específica con respecto a la argumentación en general, es el empleo de la lógica $^{7}$ (Peña, 73: 2017).

Pero, como ya se anuncia en las palabras de Peña, resulta que la mayor parte de los razonamientos que realizamos son aplicados en contextos discursivos, es decir, contextos de interacción linguística entre unos y otros. Como bien indica Luis Vega, en el terreno del discurso no solamente jugará un papel relevante la forma de nuestro razonamiento, sino que habrá que tomar en cuenta una dimensión que es pragmática, puesto que el uso del lenguaje está orientado por determinados propósitos o pretensiones argumentativas; otra que es cognitiva, la cual tiene que ver con la posibilidad de comunicar ideas y emociones, por ejemplo; y también una dimensión sociocultural, dada la relevancia de la situación y el contexto de interacción y de entendimiento entre los individuos (Vega, 5: 2017).

Todo lo anterior es tan solo una muestra de que hay una serie de conocimientos básicos que deben estar bien asentados en la formación del futuro jurista, justamente para que éste pueda comprender y desenvolverse en el conocimiento más específico de su materia. Como se verá ahora, este conocimiento es, en principio, teórico, pero implica un dominio de la teoría mucho más complicado que un mero ejercicio de

\footnotetext{
${ }^{7}$ Esto, por supuesto, tiene su propio grado de dificultad. Tal y como subraya Lorenzo Peña, lo anterior no quiere decir que exista una lógica que proporcione los insumos que destacamos como relevantes en la formación de cualquier profesional. Así, aunque sea la lógica tradicional la más extendida, las distintas áreas de conocimiento exigen también tomar en cuenta la diversidad de lógicas propuestas (de hecho, el autor en comento ha optado por defender la conveniencia de la lógica difusa). Las personas necesitamos, para razonar, la lógica, pero necesitamos también generar un criterio para saber qué lógica usar: "Ha llegado la hora de que los juristas se interesen por las lógicas para escoger su lógica. No en el aislamiento del aprendizaje individual, sino en el trabajo mancomunado y colaborativo. Tienen que razonar con lógica. Tienen que hacerlo tanto para inferir conclusiones fácticas a partir de premisas fácticas como para deducir de un cúmulo de premisas, unas fácticas y otras normativas, conclusiones normativas" (Peña, 76: 2017).
} 
reconocimiento y memorización de una serie de conceptos y proposiciones generales sobre el Derecho.

En el Derecho, como en tantos ámbitos, tenemos muy presente la afirmación de que necesitamos una teoría, una teoría del Derecho. Cuál teoría, cuál es el objeto a partir del cual se articula o cuáles son sus pretensiones es algo muy discutido que varía, incluso, de acuerdo con las distintas formas de entender ontológicamente el Derecho. Por ejemplo, desde una perspectiva iusrealista, en tanto que el Derecho se asume como una realidad ya dada, una teoría sobre el mismo tiene que ser descriptiva, es decir, limitarse a describir el Derecho tal como es en nuestras comunidades. De momento no se ahondará más en esta cuestión harto compleja; sin embargo, este ejemplo es pertinente para anotar que, pese a las discusiones que subyacen en el fondo de las distintas propuestas teóricas, debe haber algo en común que permita identificarlas, justamente, como "teorías".

Una teoría comprende distintos niveles de abstracción. El nivel más alto, el de los fundamentos, implica una reflexión ontológica y epistemológica sobre los distintos objetos de conocimiento. Podemos identificar también un nivel intermedio que comprende la cuestión interdisciplinar, es decir, el mapa de las distintas disciplinas que habrá que tomar en cuenta para dotar de coherencia a un objeto de estudio específico. Finalmente, hay otro nivel donde encontramos ya las distintas teorías que se configuran en torno al objeto de estudio (atendiendo a los anteriores niveles), las cuales se disputan la pertinencia para dar cuenta del fenómeno en concreto de mejor manera, así como para fijar problemas relacionados con éste y plantear su solución. Es en este nivel donde encontramos distintas proposiciones generales y conceptos que dotan de sistematicidad al estudio de una disciplina ${ }^{8}$.

Así, por ejemplo, en el caso del Derecho, por lo menos desde el siglo XIX, todo intento de sistematización en torno al Derecho que ha sido identificado como teoría ha propuesto una caracterización de determinados conceptos básicos como los de norma,

\footnotetext{
${ }^{8}$ Por ejemplo, Bobbio al plantear la cuestión del positivismo jurídico y distinguir los distintos sentidos del mismo, señala que entiende por teoría "un conjunto de aseveraciones vinculadas entre sí con las cuales cierto grupo de fenómenos son descritos, interpretados, llevados a un nivel muy alto de generalización y unificados después en un sistema coherente; no el modo de acercarse a una determinada realidad, sino el modo de entenderla, de dar una descripción y una explicación global de ella" (2007: 45).
} 
acción, deber jurídico, sistema jurídico, sanción, derecho subjetivo, etcétera (aunque las discusiones relevantes entre las escuelas del pensamiento jurídico tienen que ver con desacuerdos en el nivel de los fundamentos). Esto es relevante porque, tal y como señala Fernando Leal, con frecuencia creemos (equivocadamente) que el conocimiento de la teoría como tal radica en la familiarización con los conceptos y términos clave de la misma:

Cuando alguien se enfrenta por vez primera a una teoría, lo primero con lo que se topa es con un vocabulario especializado, es decir un buen número de términos técnicos, de definiciones de ellos, de abreviaturas, acrónimos y frases hechas, de las correspondientes distinciones conceptuales, clasificaciones y tipologías. Dicho toscamente, es toda una jerga nueva. El principiante se aplica a aprender la jerga, a utilizar los términos, a repetir las definiciones, a distinguir las cosas que dentro de ella son distintas, a categorizar y clasificar las cosas de acuerdo con la jerga, a citar los pasajes apropiados en que los autores clásicos o de moda la utilizan. Todo eso está muy bien, y con ello puede uno lucirse y parecer que sabe uno algo; pero si el principiante no ha aprendido más, entonces no se ha aprendido teoría ninguna, sino justamente sólo una jerga; ha aprendido la jerga de la teoría, pero no la teoría misma... (Leal, 2013: 17).

Con lo anterior, el autor denuncia la falta de claridad que hay acerca de lo que es genuinamente la teoría. El conocimiento de la misma no consiste en el dominio de un vocabulario especializado, sino que éste es solamente un instrumento, una herramienta que facilita el genuino aprendizaje de la teoría, el cual consiste en conocer las proposiciones fundamentales de la teoría para valernos de ellas en la resolución de problemas mediante el uso de procedimientos específicos (Leal, 2013: 13).

Las reflexiones de Leal nos permiten comenzar a trazar un primer vínculo definido entre teoría y práctica: las teorías se utilizan o sirven para atender problemas que son prácticos. El conocimiento teórico no consiste, entonces, en el dominio memorístico de conceptos y proposiciones generales de la teoría, sino en la capacidad de utilizarlos para resolver los propios problemas que son la fuente de la teoría y que, a su vez, pueden ser precisados como tales gracias a la misma.

Esto quiere decir que cuando pensamos en una teoría como la del Derecho, ésta no tiene el propósito de la mera elucubración: detrás del esclarecimiento de cuestiones como qué es Derecho y qué implica que algo sea considerado como tal, subyace la determinación 
de un problema consistente, por ejemplo, en qué deben hacer los ciudadanos ante una diversidad de instrumentos que demandan el cumplimiento de pautas de conducta que imponen limitaciones a algunos de sus intereses. La propia propuesta teórica permite delimitar el problema y también ofrecer una solución: por ejemplo, que en estos casos los ciudadanos están ante un tipo de normas identificadas como regulativas que establecen permisos y pautas de comportamiento 9 (deberes o prohibiciones), las cuales deben ser observadas, puesto que su cumplimiento contribuye a la armonía social; de lo contrario, su inobservancia dará lugar a consecuencias jurídicas que serán aplicadas coercitivamente por personas autorizadas para ello. Esto pone de manifiesto, de nuevo, un síntoma de la inseparabilidad de la teoría y la práctica: una máxima, como la que se acaba de anotar, es el resultado de la sabiduría práctica, de ahí que resulte efectivamente útil para guiar la toma de una decisión.

Considerando todo lo antes expuesto, puede sostenerse que cuando se reclama que la enseñanza del Derecho es demasiado teórica es posible que se esté aludiendo a dos situaciones distintas (o a ambas): Por un lado, se puede estar haciendo referencia a un método de enseñanza que se queda en ese nivel superficial de conocimientos de la “jerga" jurídica y los instrumentos positivos vigentes. Por otro lado, puede estarse aludiendo a cierto contenido teórico que dificulta el entendimiento práctico, en el sentido de que esa teoría no permita atender y resolver los problemas de quienes deben operar con el Derecho.

Aquí se sostiene que la denuncia de que la educación jurídica es poco práctica es correcta, y que ello es así no porque sea excesivamente teórica, sino porque no hay una adecuada comprensión de la teoría. La dificultad radica, entonces, en pasar por alto la interrelación entre un nivel y otro. Y es que en un ámbito del conocimiento como el Derecho, centrado en la resolución de conflictos y en favorecer la cooperación, no es

\footnotetext{
${ }^{9}$ Sobre las normas que establecen deberes o prohibiciones (normas de mandato), Atienza y Ruiz Manero establecen lo siguiente: "En las normas de mandato, esta función de guía de conducta se lleva a cabo estipulando, bien la obligación de realizar una determinada acción $p$ en un determinado caso $q$ (o, lo que es lo mismo, la prohibición de omitir realizar $p$ en $q$ ), bien la prohibición de realizar $p$ en $q$ (o, lo que es lo mismo, la obligación de omitir $p$ en $q$. Esto es, las normas de mandato, que pueden expresarse bajo la forma de obligaciones o de prohibiciones, ordenan, bien realizar una determinada acción, bien omitirla y, así, deslindan la esfera de lo lícito de la de lo ilícito)" (2007: 115 y 116).
} 
posible que algo funcione y tenga sentido en la teoría, pero no en la práctica; en realidad, esto debe tomarse como un indicio de un defecto teórico importante. Por ello, el solo planteamiento de la oposición entre teoría y práctica da cuenta de que en la educación jurídica se está reproduciendo una teoría-1, pero especialmente 2- poco adecuada.

\section{Una teoría del Derecho poco adecuada para la práctica del Derecho}

A continuación se analizarán algunos planteamientos sustantivos, muy arraigados en la tradición jurídica -las cuales forman parte de cierto contenido de teoría 2-, que alimentan la idea de que hay una oposición entre la teoría y la práctica del Derecho y que, según se argumentará, resultan especialmente perjudiciales para la formación de los futuros juristas.

De entre todos los planteamientos sobre el Derecho que resultan cuestionables y que, sin embargo, impregnan la educación jurídica se pueden subrayar tres:

a) La enseñanza del Derecho como un fenómeno ya dado, cuya única dimensión relevante es la autoritativa.

b) La enseñanza del instrumental jurídico -el Derecho positivo- como algo que debe ser memorizado. Si el Derecho consiste básicamente en normas, entonces el buen jurista es el que conoce el mayor número de ellas ${ }^{10}$.

c) La enseñanza de la dogmática jurídica como si se tratara de un conocimiento terminado que solo hay que reproducir y transmitir.

Estos tres planteamientos, redirigidos a la educación del Derecho, son propios de lo que se conoce como formalismo jurídico. Este formalismo se caracteriza por concebir al Derecho como un sistema autosuficiente de reglas, capaz de dar respuesta a cualquier caso; se trata, por tanto, de un sistema libre de lagunas, contradicciones e indeterminaciones que sólo requiere ser aprehendido en su literalidad. Asimismo, el

\footnotetext{
${ }^{10}$ Frederick Schauer señala cómo este aspecto es, además, el que más se relaciona con la actividad jurídica: "El razonar con reglas quizás sea la imagen más común que se tiene de lo que hacen los abogados y los jueces. Una concepción popular muy extendida supone que los abogados fundamentan sus casos mediante la apelación a reglas abstrusas, incomprensibles para el común de la gente, y que los jueces toman sus decisiones después de consultar libros repletos de esas reglas. Se cree que una vez que encuentra la regla correcta, el juez procede a aplicarla mecánicamente al caso que juzga, y ese es el fin del asunto. Los juristas más refinados suelen burlarse de esta imagen que coloca a los operadores jurídicos muy lejos de sus prácticas reales" (Schauer, 2013: 29).
} 
formalismo parte de una idea del Derecho como un conjunto de normas ${ }^{11}$ - un objetoque lleva a sus usuarios a tener una concepción del Derecho de tipo normativista, según la cual éste consiste únicamente en un fenómeno autoritativo (normas como mandatos de autoridad), sin una dimensión valorativa.

Si bien pocos juristas se reconocen abiertamente como formalistas, puede sospecharse que éste sigue siendo el gran enemigo de la educación jurídica ${ }^{12}$, dado que sigue siendo el contenido de la teoría 2 en la que formamos a los estudiantes. Un jurista formalista, reproduce en sus actividades -tanto docentes como de otro tipo- una concepción del Derecho - una teoría- normativista.

De acuerdo a las situaciones antes anotadas, esto propicia en las aulas: (a) un razonamiento jurídico que prescinde de la moral y la política, tomando como razón justificante del Derecho el mero carácter autoritativo de las leyes; (b) una actividad docente centrada en enseñar o transmitir conocimientos a los estudiantes sin mediar ningún tipo de reflexión crítica, premiando la importancia de conocer el Derecho positivo como objeto contemplativo; y (c) un tratamiento de la dogmática como si se tratara de un conjunto de conceptos y sistematizaciones cerrado, descriptivo, amoral y apolítico $^{13}$.

\footnotetext{
${ }^{11}$ De acuerdo con el planteamiento de Manuel Atienza, la idea del Derecho como sistema de normas se contrapone a la idea del Derecho como práctica social. Este autor señala que se trata de una diferencia ontológica, en cuanto alude al tipo de realidad en que consiste el Derecho. Para la primera se trataría de una realidad ya dada y estructurada de una determinada manera (un resultado), y para la segunda una realidad en formación y analizable en término de etapas de un proceso. La idea del Derecho como práctica social enfatiza que el Derecho es una empresa con la que se trata de lograr propósitos y no es exclusiva de una concepción del Derecho específica. Contiene esencialmente tres componentes: (1) una concepción dinámica del Derecho (que supone considerarlo no simplemente como un hecho social, sino como un artefacto social complejo, inventado para cumplir ciertos propósitos); (2) la distinción en una compleja realidad de la dimensión organizativa o autoritativa y una finalista o axiológica, articuladas de tal forma que la segunda no puede reducirse a la primera, gozando de preeminencia; (3) la necesaria vinculación de la práctica jurídica con valores morales objetivos o con la idea de justicia (2017: 35$)$.
}

12 Desde hace dos siglos se identifica a nuestra cultura jurídica como marcadamente formalista. Desde finales del siglo XIX se ha intentado contrarrestar esta perspectiva, pero a la fecha queda un largo trecho para ello. Un período de gran relevancia en este sentido es el de la revuelta contra el formalismo que derivó en las distintas versiones del realismo jurídico. La reacción contra los excesos del formalismo comenzó a gestarse desde finales del siglo XIX, a través de los escritos de autores como Oliver Wendell Holmes, John Dewey, John Chipman Gray o Roscoe Pound, hasta llegar a la llamada "revuelta contra el formalismo" que alcanzó su punto culminante durante los años veinte y treinta del siglo XX (Pérez Lledó, 1996: 170).

${ }_{13}$ Al respecto, es ilustradora la manera en que Manuel Atienza caracteriza el modelo tradicional de dogmática en el mundo latino: "Está profundamente anclado en el formalismo jurídico como concepción del Derecho; tiende a aislar la dogmática del resto de los saberes sociales; es reacio a la incorporación de nuevos 
métodos procedentes de la lingüística, la economía, etc.; subraya la función descriptiva y sistemática de la dogmática y tiende a negar (o a ocultar) la de carácter práctico; presenta la dogmática como un saber neutral, estrictamente separado de la política y de la moral; se centra en el Derecho formalmente válido y no en el Derecho en acción; se desentiende de los valores sustantivos del Derecho y privilegia ante todo el de la seguridad jurídica (los valores formales); propende al uso de argumentos basados en la autoridad y dirigidos a interpretar en forma preferentemente literal las normas, mientras que es reacio a la utilización de argumentos teleológicos o valorativos (2017: 80 y 81). 
Con esto, interesa destacar dos cosas.

(1) Detrás de práctica 1 siempre hay una teoría 1 y también una teoría 2. En primer lugar, porque cualquier profesional del Derecho, necesariamente, para hacer un análisis jurídico necesita de herramientas que le permitan plantear un razonamiento. Sin embargo, es obvio que, en la medida en la que estas herramientas sean precisas y estén organizadas, estará mejor capacitado para ello. Así, todo jurista que se precie de razonar jurídicamente requiere de una formación metodológica general que, sin embargo, no pase por alto las perspectivas pragmáticas del contexto jurídico ${ }^{14}$.

Ahora bien, cuando los profesionales del Derecho afrontan problemas prácticos lo que hacen es un uso instrumental del Derecho, lo que quiere decir que no se trata de problemas para los que haya una solución explícita o implícitamente contenida en las normas, como sostendría la teoría formalista y, según se revisó, como se concluiría de una mala comprensión del conocimiento teórico. Es por ello que necesitan una teoría 2 óptima que les permita usar el Derecho para resolver esos problemas prácticos. Lo que sucede es que, tal como señala Alejandro Nieto, si admitimos que el Derecho es un instrumento -un medio- lo que sigue es cuestionar ¿al servicio de qué o de quién ${ }^{15}$ (2007: 41).

(2) La búsqueda de una respuesta a esta pregunta permite pasar a la siguiente cuestión: hay formas de concebir el Derecho, teorías, que son idóneas para dirigir la práctica, de tal forma que el Derecho no solo sirva para resolver problemas prácticos, sino para que ese uso instrumental $-\mathrm{y}$, por tanto, la forma y la solución de esos problemas- esté orientado a los valores que le son propios, que lo legitiman.

\section{Una teoría al servicio de la práctica del Derecho}

\footnotetext{
${ }^{14}$ Es esto sí me atrevería a conceder que puede tener razón el reclamo de abstracción. Y es que aun tratándose de teoría 1 ha de procurarse dar cuenta del punto de vista de quienes usan el Derecho. "Uno de los defectos graves de la forma como se enseña el Derecho en nuestras Universidades es que, por lo general, no se lo presenta desde ninguno de esos puntos de vista que permiten ver al Derecho en un contexto práctico" (Carrió, 1995: 27 y 28).

${ }^{15}$ Nieto concluye que las numerosas respuestas que se han ofrecido a lo largo de la historia giran en torno a dos polos: un valor o el poder: "La fórmula teóricamente más extendida es la axiológica: el Derecho está al servicio de algún valor superior, como la justicia, el orden o el bien común. En el extremo opuesto se le coloca al servicio del poder: la voluntad del soberano o la de los representantes del pueblo" (2007: 41). Hay que tener presente que junto a esta reflexión de Nieto se encuentra la defensa de una posición metaética relativista.
} 
La última reflexión anotada, respecto a la conveniencia de considerar otras propuestas teóricas, distintas de la opción formalista, para utilizar el Derecho e intentar alcanzar algo determinado con éste, nos permitirá reconstruir finalmente la interrelación entre la teoría y la práctica del Derecho. Este sentido esclarecido de ambos conceptos, teoríapraxis, sí es relevante para dar cuenta del razonamiento que realizan los (buenos) juristas prácticos.

Para ello, sin embargo, es necesario plantear la cuestión del tipo de actividades que se realizan en las profesiones jurídicas. Cruz Parcero señala una serie de actividades básicas -no exhaustivas- que realizan los juristas. Por ejemplo: 1) identifican el objeto de su estudio; 2) describen las normas contenidas en las leyes; 3) sistematizan el Derecho; 4) definen, crean y utilizan conceptos; 5) elaboran y utilizan distinciones, clasificaciones y teorías; 6) infieren los principios subyacentes en el ordenamiento; 7) interpretan las normas; 8) analizan y describen hechos; 9) argumentan a favor o en contra de decisiones; 10) reflexionan sobre valores jurídicos y emiten juicios; 11) predicen lo que harán los jueces o funcionarios; 12) legitiman o critican los regímenes políticos; 13) enseñan, transmiten y difunden sus conocimientos (2006: 19 y 20).

Este listado permite ilustrar la variedad de actividades que realizan los juristas prácticos, así como el tipo de problemas que deben afrontar en ellas. Pero, además de dar cuenta de la variedad es necesario enfatizar que todas ellas son susceptibles de ser caracterizadas como actividades profesionales.

Una actividad profesional es, de acuerdo con Adela Cortina, una actividad social cooperativa. Para analizar qué quiere decir esto, Cortina nos remite al concepto de praxis aristotélica -además de la propuesta conceptual de Alasdar MacIntyre-, según el cual la praxis (acción) - a diferencia de la poiesis (producción)- es un tipo de acción que no se realiza para dar lugar a un resultado distinto de ella misma; es decir, posee su propio fin en sí misma. Así, la práctica es una actividad social cooperativa que cobra sentido -su racionalidad específica y su legitimidad social- en tanto que tiende a alcanzar unos bienes que son internos a ella misma y que ninguna otra puede proporcionar (Cortina y Martínez, 2001: 161). "Las distintas actividades se caracterizan pues, por los bienes que solo a través de ellas se consiguen, por los valores que en la persecución de esos fines se descubren y por las virtudes cuyo cultivo exigen" (Cortina y Martínez, 2001: 162). 
Con esto, lo que se trata de indicar es que, cuando un profesionista tiene que hacer uso del conocimiento teórico del Derecho, lo hace a la luz de unos fines determinados que deberían reproducir los bienes internos que justifican a las profesiones jurídicas. Si bien es cierto que los fines se modulan en función de la posición pragmática de cada jurista por ejemplo, si se trata de un abogado, los intereses de sus clientes tienen un lugar privilegiado-, esto no significa que los fines vayan a fijarse en función de los intereses en turno; estos fines, que dan vida a los bienes internos de la profesión, requieren ser esclarecidos en el nivel de teoría 2, aunque están directamente relacionados con lo que ya se señalaba de práctica 2.

Una concepción del Derecho implica un conjunto de ideas acerca de qué cuenta como Derecho, pero también de cómo debería ser ese Derecho y qué se pretende lograr con él. Dicho en otras palabras, se trata del espacio en el que ha de darse la reflexión profunda y general del Derecho para conocerlo, criticarlo, cambiarlo, etc. En este sentido son significativas las palabras de Holmes cuando señala que "no debe temerse a la teoría como algo poco práctico, porque, para el jurista competente, la misma significa sencillamente ir al fondo de la materia" (2012: 90).

Así, por ejemplo, el profesional del Derecho que concibe a éste, ya no solo como un sistema de normas, sino como una práctica social que pretende satisfacer fines valiosos, como son la garantía y la protección de derechos individuales básicos, procurará que su actividad práctica reproduzca o abone a esos fines. Las normas e instituciones jurídicas no serán ya meras imposiciones autoritativas, sino partes de una maquinaria compleja que tiende a lograr un mundo más justo; así, no buscará que su práctica sea buena simplemente en términos técnicos, sino que sea una práctica justificada. La dimensión autoritativa del Derecho es inseparable así de una dimensión valorativa que permite a ese profesional hacer un uso reflexivo del Derecho, un ejercicio práctico del Derecho.

De esta forma, el Derecho es, ciertamente, un instrumento, pero también es el marco de realización de fines valiosos. El Derecho posee una dimensión práctica en la que se 
pretenden generar razones justificativas ${ }^{16}$ respecto al ejercicio del poder y a la protección de unos intereses frente a otros.

\section{Teoría-praxis del Derecho y la enseñanza jurídica}

Teoría y práctica están, entonces, interrelacionadas de muchas maneras, destacando las siguientes:

En primer lugar, porque el conocimiento teórico permite establecer un punto de partida con el cual contrastar los problemas prácticos que se nos presentan. Se trata de una especie de operación mental en la que el buen jurista práctico desarrolla la facultad de discernir si el problema concreto al que tiene que dar solución corresponde o no con las proposiciones generales que conoce de su disciplina ${ }^{17}$. Es decir, se trata de un enlace que conecta el entendimiento de los conceptos, nociones y principios generales del Derecho y la acción de reflexionar los casos prácticos conforme a ese sistema teórico, para encontrar una solución mediante procedimientos específicos (por ejemplo, el procedimiento de la subsunción o de la ponderación en casos de decisiones judiciales). Además, a menos que se defienda la idea de un sistema cerrado y completo, hay que asumir que esa teoría es incompleta y no siempre permitirá deducir la solución de ella. Esto, sin embargo, lejos de ser motivo de recriminación a la teoría, da cuenta de una interrelación viva, puesto que, la teoría, para cumplir con su propósito de ser un saber útil, ha de robustecerse y combatir su incompletitud con base a la experiencia de los propios casos. En definitiva, como señala Kant:

\footnotetext{
${ }^{16}$ Como señala Victoria Roca, cuando se alude a la razón en el sentido de razón justificativa, no se está en el nivel discursivo de explicar por qué una persona realizó una acción o intentando predecir cómo se llevará a cabo; se hace referencia, más bien, a la necesidad de justificar o valorar esa acción, es decir, determinar si fue correcta o incorrecta desde un punto de vista moral, prudencial o jurídico (2005: 191).

${ }^{17}$ Sobre esto último resultan ilustradoras las palabras de Altarejos y Naval cuando señalan lo siguiente: "Cualquier práctica social debe regirse por un saber práctico. Esto es indudable e indiscutido. Lo que ya no parece tan firme es que el saber práctico deba constituirse y desarrollarse desde la práctica; si se atienden a las bases culturales de la modernidad, parece más bien que el saber práctico se deriva del saber teórico, del cual se considera una aplicación o proyección. El esquema es el siguiente: el saber teórico contiene los principios supremos y las verdades universales del conocimiento de los seres; de tales principios y verdades se derivan las normas de actuación práctica, que tienen entonces un sentido correctivo: eliminar los aspectos de los seres u objetos que no se correspondan con el modelo teórico y universal. La regulación racional de dichas acciones correctoras es el contenido del saber práctico, que resulta así fundado en el saber teórico, y concebido como saber técnico" (2011: 59).
} 
Nadie puede decirse prácticamente versado en una ciencia y a la vez despreciar la teoría, pues así mostraría simplemente que es un ignorante en su oficio, en cuanto cree poder avanzar más de lo que le permitiría la teoría mediante ensayos y experiencias hechos a tientas sin reunir ciertos principios (que propiamente constituyen lo que se llama teoría) y sin haber pensado su tarea como un todo... (2004: 8 y 9)

En segundo lugar, porque, retomando el concepto de práctica 2, de lo pragmático, se trata de reconocer que el Derecho es un instrumento y, por tanto, tiene que servir para algo. Ya se avanzó en que, sin embargo, ese "servir para algo" no puede ser ciego, sino que debe responder a una guía que resulta de la propia reflexión sobre los bienes internos de la actividad social cooperativa que es la práctica profesional del Derecho.

Para cerrar esta idea conviene retomar la reflexión de Manuel Atienza al manifestar que el trasfondo filosófico de una concepción del Derecho adecuado para los Derechos del Estado Constitucional tiene que ser el pragmatismo, entendido como una forma de entender la teoría jurídica cuyo rasgo central es la primacía de la práctica. Con esto, no se refiere a una filosofía del Derecho, sino a una actitud que se necesita para construir una filosofía del Derecho con sentido, capaz de incidir en las prácticas jurídicas ${ }^{18}$ (2019: 159).

\section{Conclusiones}

A lo largo de estas páginas se ha intentado mostrar cómo lo teórico y lo práctico están necesariamente relacionados, por lo que insistir en una oposición entre ellos solo genera una fractura en la enseñanza jurídica que es autofrustrante. Esta falsa oposición hasta ahora puede haber jugado un papel en la reflexión del tipo de saberes que un profesional del Derecho necesita, pero conviene ser conscientes de las escisiones innecesarias y los enfrentamientos infértiles a los que esta falacia da lugar en nuestras instituciones educativas. Quizá nos percatemos así de que la oposición entre lo teórico y lo práctico está llevando, sobre todo, al desaprovechamiento de considerables esfuerzos académicos. Para ilustrar esto, se cierra con la reflexión del mismo filósofo con el que se inició este documento:

\footnotetext{
${ }^{18}$ Sobre este sentido del pragmatismo agrega que “... no podía tratarse del pragmatismo ramplón del jurista que vive al ras del suelo y que no es capaz de entender que en el Derecho se necesitan teorías precisamente para poder ser suficientemente prácticos... Tenía que ser un pragmatismo no meramente instrumentalista..." (Atienza, 2019: 159).
} 
Cuando un grupo de hormigas está transportando un objeto, muchas de ellas tiran en sentidos opuestos; una parte considerables de su esfuerzo se inutiliza. El objeto, sin duda, acabará por ir adonde tenía que ir, debido a la predominancia de ciertos esfuerzos sobre otros; pero da lástima ver el esfuerzo inútilmente perdido. Absolutamente este mismo espectáculo ofrecería la humanidad pensante al que de pronto se despertara completamente de este sofisma, como de una alucinación (Vaz Ferreira, 79: 26).

\section{Bibliografía}

ALTAREJOS, F. y NAVAL, C. (2011): Filosofía de la Educación. Tercera edición. EUNSA Ediciones Universidad de Navarra, colección filosófica No. 154. Navarra, España.

ATIENZA RODRÍGUEZ, M. (2019): Comentarios e incitaciones. Una defensa del postpositivismo jurídico. Editorial Trotta. Madrid, España.

ATIENZA RODRÍGUEZ, M. (2017). Filosofía del Derecho y transformación social. Editorial Trotta. Madrid, España.

ATIENZA RODRÍGUEZ, M. y RUIZ MANERO, J. (2007): Las piezas del Derecho: teoría de los enunciados jurídicos. Editorial Ariel. Barcelona, España.

BOBBIO, N. (2007): El problema del positivismo jurídico. Editorial Fontamara. Ciudad de México, México.

BÖHMER, M. F. (1999): “Introducción” en La enseñanza del Derecho y el ejercicio de la abogacía. Editorial Gedisa. Barcelona, España; pp. 13-24.

CARRIÓ, G. R. (1995): Cómo estudiar y cómo argumentar un caso. Consejos elementales para abogados jóvenes. Editorial Abeledo-Perrot. Buenos Aires, Argentina. CRUZ PARCERO, J. A. (2006) "Los métodos para los juristas" en Observar la ley. Ensayos sobre metodología de la investigación jurídica (edición de Christian Courtis). Editorial Trotta. Madrid, España; pp. 17-40.

CORTINA, A. y MARTÍNEZ NAVARRO, E. (2001): Ética. Ediciones Akal. Madrid, España.

FIX-ZAMUDIO, H. (1995): “Algunas reflexiones sobre la enseñanza del Derecho en México y Latinoamérica" en Antología de estudios sobre enseñanza del Derecho 
(coordinado por Jorge Witker V.) Universidad Nacional Autónoma de México. México, pp. 77-92.

KANT, I. (2004): Teoría y praxis. El Cid Editor. Santa Fe, Argentina.

LARIGUET, G. (2015): “La investigación filosófica: ¿Análisis conceptual versus análisis histórico?” en Revista Praxis Filosófica Nueva serie, No. 42, pp. 219- 244.

LEAL, F. (2013): “Acerca de la teoría" en Revista Espiral. Estudios sobre Estado y Sociedad, Vol. XX, No. 57, pp. 9-38.

NIETO, A. (2007): Crítica de la razón jurídica. Editorial Trotta. Madrid, España.

NINO, C. S. (1988): “La discusión crítica en nuestro medio académico". Entrevista publicada en Lecciones y Ensayos No. 50, pp. 277-285.

NUSSBAUM, M. (2016): "Educación para el lucro, educación para la libertad" en Revista Nómadas, No. 44, pp. 13-25.

PEÑA, L. (2017): Visión lógica del Derecho. Una defensa del racionalismo jurídico. Editores Plaza y Valdés. Madrid, España.

PEREDA, C. (2011) "Falacia" en Compendio de lógica, argumentación y retórica (Edición de Luis Vega Reñón y Paula Olmos Gómez). Editorial Trotta, Madrid, España, pp. 249-253.

PÉREZ LLEDÓ, J. A. (1996): El movimiento Critical Legal Studies. Editorial Tecnos. Madrid, España.

PÉREZ LLEDÓ, J. A. (2002): “Teoría y práctica en la enseñanza del Derecho” en Anuario de la Facultad de Derecho de la Universidad Autónoma de Madrid no. 6, 197268.

SCHAUER, F. (2013): Pensar como un abogado. Una nueva introducción al razonamiento jurídico. Editorial Marcial Pons. Madrid, España.

VAZ FERREIRA, C. (1979): Lógica viva. Moral para intelectuales. Editorial Biblioteca Ayacucho. Caracas, Venezuela.

VEGA- REÑÓN, L. (2017): Lógica para ciudadanos. Ensayos sobre lógica civil. Editorial Académica Española. Saarbrücken, Alemania.

ROCA PÉREZ, V. (2005): Derecho y razonamiento práctico en la obra de C. S. Nino. Centros de estudios políticos y constitucionales, Madrid.

WENDELL HOLMES, O. (2012): La senda del derecho. Marcial Pons, Madrid. 